\title{
Anesthetic effect of propofol combined with remifentanil or sevoflurane anesthesia on patients undergoing radical gastrectomy
}

\author{
YAZHEN FENG $^{1 *}, \mathrm{JI} \mathrm{LI}^{2 *}$, HUSHAN WANG $^{1}$ and ZONGSHENG DUAN ${ }^{1}$ \\ ${ }^{1}$ Department of Anesthesiology and ${ }^{2}$ Operation Room, The First Bethune Hospital of Jilin University, \\ Changchun, Jilin 130021, P.R. China
}

Received August 20, 2018; Accepted March 28, 2019

DOI: $10.3892 / \mathrm{ol} .2019 .10238$

\begin{abstract}
Anesthetic effect of propofol combined with remifentanil or sevoflurane intravenous anesthesia on patients undergoing radical gastrectomy was evaluated. The clinical data of 516 cancer patients who received radical gastrectomy in the First Bethune Hospital of Jilin University between January 2011 and December 2017 were retrospectively analyzed. In total 203 patients with propofol combined with remifentanil anesthesia were used as group A, and 313 patients with propofol combined with sevoflurane anesthesia as group B. The changes of respiration and circulation were analyzed at the time of entering the operating room ( $\mathrm{t} 0)$, the beginning of the operation ( $\mathrm{t} 1), 10 \mathrm{~min}$ after the beginning of the operation $(\mathrm{t} 2)$ and $10 \mathrm{~min}$ after operation (t3). The onset time of anesthesia, the total time of operation, the time of waking up after operation and the time of leaving the operating room were analyzed. The effects of sedation and amnesia were evaluated, and the occurrence of adverse reactions were recorded. The inhibition of circulation and respiration was more obvious at $\mathrm{t} 1$ and $\mathrm{t} 2 \mathrm{in}$ group $\mathrm{A}$ when compared to group $\mathrm{B}(\mathrm{P}<0.05)$, and the respiration and circulation in group $\mathrm{B}$ was more stable than that in group $\mathrm{A}(\mathrm{P}<0.001)$. Patients' sedation scores in group $\mathrm{A}$ were lower than those in group B, and the difference was statistically significant $(\mathrm{P}<0.05)$; there were $56(27.59 \%)$ patients and $30(9.58 \%)$ patients with postoperative pain in group A and group $\mathrm{B}$, respectively $(\mathrm{P}<0.001)$. The application of propofol combined with sevoflurane in the anesthesia of patients undergoing radical gastrectomy can make the respiration and circulation more stable, and reduce the incidence of postoperative pain and adverse reactions.
\end{abstract}

Correspondence to: Dr Zongsheng Duan, Department of Anesthesiology, The First Bethune Hospital of Jilin University, 71 Xinmin Street, Changchun, Jilin 130021, P.R. China

E-mail: dwb4dq@163.com; duanzsh@126.com

${ }^{*}$ Contributed equally

Key words: propofol, sevoflurane, cancer patient, anesthetic effect

\section{Introduction}

Gastric cancer, which greatly endangers human health, is a disease with high mortality and poor prognosis $(1,2)$. Studies have suggested that the morbidity and mortality of gastric cancer will continue to increase in the coming 2-3 decades in China, making it the number one killer threatening the health of the Chinese $(3,4)$. Due to environmental pollution, food safety issues, unhealthy lifestyle and other reasons, the incidence of gastric cancer shows a trend of rejuvenation and normality. Most gastric cancer patients receive preoperative chemotherapy, but chemotherapy drugs damage their liver, heart and kidney $(5,6)$. Therefore, gastric cancer patients suffer from large trauma, severe pain and a series of severe stress responses during surgical treatment, as well as more complications after operation (7). The induction period of anesthesia is the most easily fluctuating period of respiration and circulation during the whole anesthesia period, so it is beneficial to the recovery of patients to choose the appropriate anesthetic drugs, helping them pass the anesthesia period (8-10). Remifentanil, propofol and sevoflurane are new short-acting anesthetics characterized by rapid action and rapid recovery after anesthesia, suitable for surgical anesthesia in cancer patients (11). Sevoflurane is an inhaled anesthetic with muscle relaxant effect, so it can reduce the dosage of muscle relaxant in operation; propofol has a short-time effect on anesthesia, and patients recover quickly after operation (12). Remifentanil is an opioid receptor agonist with rapid onset and short duration of maintenance (13). Study of Recart et al (14) shows that the combined use of inhaled anesthetics and opiates can reduce the dosage of anesthetics, help to stabilize the vital signs of patients undergoing surgery and reduce the incidence of postoperative adverse reactions. In this study, a retrospective cohort study was performed to analyze patients undergoing radical gastrectomy who had received previous surgical treatment, and to observe the anesthetic effect of propofol combined with remifentanil and propofol combined with sevoflurane in cancer patients in order to provide a basis for the selection of clinical anesthetic methods for cancer patients.

\section{Patients and methods}

Study subjects. A retrospective cohort study was performed to analyze the clinical data of 516 patients undergoing radical 
gastrectomy in the First Bethune Hospital of Jilin University (Changchun, China) between January 2011 and December 2017. Of the patients 203 with propofol combined with remifentanil anesthesia were group A, and 313 patients with propofol combined with sevoflurane anesthesia were group B according to the anesthetic methods accepted by patients.

The study was approved by the Ethics Committee of the First Bethune Hospital of Jilin University (no. Jlsyd2011011). Signed informed consents were obtained from the patients or the guardians.

Inclusion criteria were: Patients whose ASA was grade I or grade II, with no obvious abnormality in the function of heart, lung, liver and kidney as well as respiratory system, no history of taking opioids and drug abuse, no allergy history, no contraindications for the use of anesthetics such as propofol and sevoflurane, no history of long-term use of analgesic and sedative were included. Under the guidelines for radical gastrectomy (15), surgical procedures of all patients were standardized. Exclusion criteria were: Patients with perioperative large blood transfusion or hemorrhage, patients with a history of endocrine and immune diseases, patients who received hormone therapy, radiotherapy and chemotherapy before operation and patients with cognitive dysfunction and mental illness.

Anesthetic methods. The venous access was opened after the patient entered the operating room, and the vital signs, such as blood pressure, heart rate, respiration and oxygen saturation were closely monitored. Patients in the two groups were given general anesthesia with tracheal intubation. The induction scheme was as follows: midazolam $0.05 \mathrm{mg} / \mathrm{kg}$ and fentanyl $3.0 \mu \mathrm{g} / \mathrm{kg}$. During induction, the tidal volume was controlled at $8-10 \mathrm{ml} / \mathrm{kg}$, the end expiratory $\mathrm{CO}_{2}$ pressure was $30-40 \mathrm{mmHg}$, the ventilation frequency was $12 \mathrm{~min}$, and the breathing ratio was 1:2. When bispectral index (BIS) was $<60$, $0.10 \mathrm{mg} / \mathrm{kg}$ of vecuronium bromide was injected. Patients in group A were assisted to breathe after falling asleep, and trace intravenous infusion of propofol $7.5 \mathrm{mg} / \mathrm{kg} / \mathrm{h}$ and remifentanil $0.08 \mu \mathrm{g} / \mathrm{kg} / \mathrm{min}$ were used to maintain anesthesia. Drugs were withdrawn $5 \mathrm{~min}$ before the end of the operation. Patients in group B were assisted to breathe after falling asleep, and trace intravenous infusion of propofol $7.5 \mathrm{mg} / \mathrm{kg} / \mathrm{h}$ and $2 \%$ of sevoflurane were used to maintain anesthesia. During the operation, the doses of propofol and remifentanil were adjusted according to patients' BIS and hemodynamic parameters. Patient's BIS ranged from 40 to 55, and the blood pressure fluctuated within $20 \%$ of the baseline value.

Observation indicators. The mean arterial pressure (MAP), heart rate $(\mathrm{HR})$ and respiratory rate $(\mathrm{RR})$ of patients in the two groups were observed at the time of entering the operating room $(\mathrm{t} 0)$, the beginning of the operation $(\mathrm{t} 1), 10 \mathrm{~min}$ after the beginning of the operation (t2) and $10 \mathrm{~min}$ after the operation ( $\mathrm{t} 3$ ). The onset time of anesthesia, the total time of operation, the time of waking up after operation and the time of leaving the operating room in the two groups of patients were recorded.

Sedation and amnesia in patients 15 min after operation were judged according to the standard (16). Ramsay sedation scale was used to judge sedation effect. Patient is anxious
Table I. Comparison of basic data between two groups of patients.

\begin{tabular}{lccc}
\hline Groups & $\begin{array}{c}\text { Sex } \\
\text { male, } \mathrm{n}(\%)\end{array}$ & $\begin{array}{c}\text { Age } \\
\text { (years) }\end{array}$ & $\begin{array}{c}\text { Course of } \\
\text { disease } \\
\text { (months) }\end{array}$ \\
\hline $\mathrm{A}, \mathrm{n}=203$ & $114(56.16)$ & $63.41 \pm 4.52$ & $6.24 \pm 1.68$ \\
$\mathrm{~B}, \mathrm{n}=313$ & $150(47.92)$ & $65.39 \pm 3.61$ & $6.48 \pm 1.51$ \\
$\mathrm{t} / \chi^{2}$ value & 3.341 & 3.167 & 2.171 \\
P-value & 0.068 & 0.114 & 0.254 \\
\hline
\end{tabular}

and restless, 1 point; patient coordinate, has orientation and is quiet, 2 points; patient responds to instructions, 3 points; patient responds quickly to a tap on the glabella or loud auditory stimuli, with sleepiness, 4 points; patient responds slowly to a tap on the glabella or loud auditory stimuli, with sleepiness, 5 points; patient shows no response, with sleepiness, 6 points. One point indicates insufficient sedation; 2-4 points indicate appropriate sedation; 5-6 points indicate excessive sedation. Amnesia criteria: No amnesia, can recall the surgical process when awake; incomplete amnesia, can recall some with hints; complete amnesia, cannot recall. The occurrence of adverse reactions within $24 \mathrm{~h}$ after operation was recorded.

Statistical analysis. In this study, SPSS 19.00 (SPSS, Inc., Chicago, IL, USA) software was used to perform statistical analysis on the data, and Graph Pad 7 was used to draw illustrations. The count data were presented as (\%), and were analyzed using Chi-square test $\left(\chi^{2}\right)$. The grade data were presented as (\%), and were analyzed using the rank sum test $(\mathrm{Z})$. The K-S test was used to analyze the measurement data. Data conforming to the normal distribution were tested by t-test, and were expressed as mean \pm standard deviation (mean $\pm \mathrm{SD}$ ). The independent sample t-test was performed in the comparison between groups, while the paired t-test was performed in the comparison within the group. The data that did not conform to the normal distribution were expressed by quartiles indicating P50 (P25-P75), and were analyzed using nonparametric test (U). Repeated measures ANOVA was performed to analyze changes in MAP, HR and RR during treatment. Bonferroni test was the post hoc test. Statistically significant difference was set at $\mathrm{P}<0.05$.

\section{Results}

Basic patient data. There were 203 patients in group A, including $114(56.16 \%)$ males with an average age of $63.41 \pm 4.52$ years and an average course of disease of $6.24 \pm 1.68$ months; 313 patients in group B, including 150 $47.92 \%$ males with an average age of $65.39 \pm 3.61$ years and an average course of disease of $6.48 \pm 1.51$ months. The difference has no statistical significance between the two groups in sex, age and course of disease $(\mathrm{P}>0.05)$ (Table I).

Changes of respiration and circulation during perioperative period. The values of MAP (61.5 and $60.10 \mathrm{mmHg}), \mathrm{HR}(65.3$ and 
Table II. Comparison of onset time of anesthesia, total time of operation, time of waking up after operation, and time of leaving the operating room between two groups of patients (mean $\pm \mathrm{SD}$ ).

\begin{tabular}{lcccc}
\hline Groups & $\begin{array}{c}\text { Onset time of } \\
\text { anesthesia }(\mathrm{sec})\end{array}$ & $\begin{array}{c}\text { Total time of } \\
\text { operation }(\mathrm{min})\end{array}$ & $\begin{array}{c}\text { Time of waking up } \\
\text { after operation (min) }\end{array}$ & $\begin{array}{c}\text { Time of leaving the } \\
\text { operating room (min) }\end{array}$ \\
\hline $\mathrm{A}, \mathrm{n}=203$ & $55.10 \pm 11.85$ & $225.53 \pm 7.58$ & $6.20 \pm 2.12$ & $9.52 \pm 3.95$ \\
$\mathrm{~B}, \mathrm{n}=313$ & $35.20 \pm 8.26$ & $224.71 \pm 7.01$ & $4.06 \pm 1.84$ & $9.31 \pm 4.32$ \\
$\mathrm{t}$ value & 10.805 & 0.97 & 4.682 & 0.985 \\
P-value & $<0.001$ & 0.33 & 0.011 & 0.611 \\
\hline
\end{tabular}

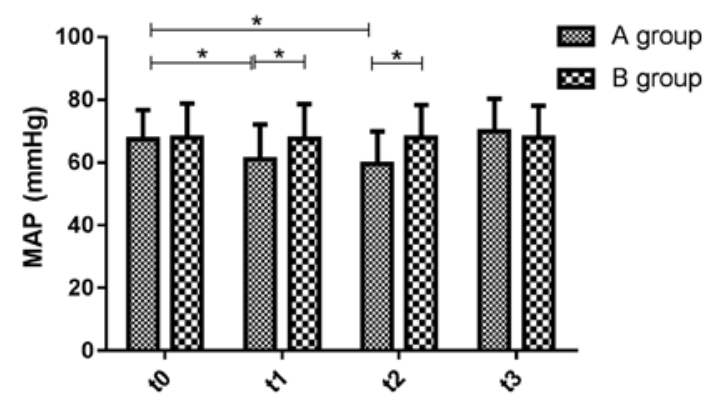

Figure 1. Comparison of MAP between two groups of patients. The figure showed that the value of MAP at $\mathrm{t} 1$ and $\mathrm{t} 2$ was lower than that at $\mathrm{t} 0$ and the difference between at $\mathrm{t} 3$ and at $\mathrm{t} 0$ has no statistical significance in group $\mathrm{A}$ $(\mathrm{P}>0.05)$; the value of MAP at $\mathrm{t} 1, \mathrm{t} 2$ and $\mathrm{t} 3$ was not different from that at $\mathrm{t} 0$ in group $\mathrm{B}(\mathrm{P}>0.05)$. The value of MAP at $\mathrm{t} 1$ and $\mathrm{t} 2$ in group $\mathrm{B}$ was higher than that in group A $(\mathrm{P}<0.05)$, and the difference of the value of MAP at $\mathrm{t} 3$ between two groups has no statistical significance $(\mathrm{P}>0.05) .{ }^{*} \mathrm{P}<0.05$. The time of entering the operating room ( $\mathrm{t} 0)$, the beginning of the operation ( $\mathrm{t} 1$ ), $10 \mathrm{~min}$ after the beginning of the operation (t2) and $10 \mathrm{~min}$ after operation ( $\mathrm{t} 3$ ).

66.1 times/min) and RR (11.20 and 10.50 times/min) at $\mathrm{t} 1$ and $\mathrm{t} 2$ were lower than those at $\mathrm{t} 0(67.8,77.2$ and 14.6 times $/ \mathrm{min})$ $(\mathrm{P}<0.05)$, and the value of $\mathrm{RR}(18.7$ times $/ \mathrm{min})$ at $\mathrm{t} 3$ was higher than that at $\mathrm{t} 0(\mathrm{P}<0.05)$ in group $\mathrm{A}$; the values of MAP $(68.6$, 67.8 and $67.9 \mathrm{mmHg}), \mathrm{HR}(76.8,76.2$ and 78.10 times/min) and RR (14.6, 15.1 and 14.8 times/min) at $\mathrm{t} 1, \mathrm{t} 2$ and $\mathrm{t} 3$ were not different from that at $\mathrm{t} 0(68.1 \mathrm{mmHg}, 77.3$ and 15.3 times $/ \mathrm{min})$ $(\mathrm{P}>0.05)$ in group $\mathrm{B}$. The values of MAP, HR and RR at $t 1$ and $\mathrm{t} 2$ in group $\mathrm{B}$ were higher than those in group $\mathrm{A}(\mathrm{P}<0.05)$, and the value of $\mathrm{RR}$ at $\mathrm{t} 3$ was lower than that in group $\mathrm{A}(\mathrm{P}>0.05)$ (Figs. 1-3).

Comparison of onset time of anesthesia, total time of operation, time of waking up after operation, and time of leaving the operating room between the two groups. The onset time of anesthesia and the time of waking up after operation in group B were shorter than those in group A, and the difference has statistical significance $(\mathrm{P}<0.001, \mathrm{P}=0.011)$; the difference has no statistical significance $(\mathrm{P}=0.251, \mathrm{P}=0.611)$ between group $\mathrm{A}$ and group $\mathrm{B}$ in the total time of operation and the time of leaving the operating room. Specific information is shown in Table II.

Sedation score and amnesia after operation. The sedation score of patients in group A was lower than that in group B, and the difference has statistical significance $(\mathrm{P}<0.05)$; there was no statistical significance difference between the two groups in amnesia $(\mathrm{P}>0.05)$ (Table III).

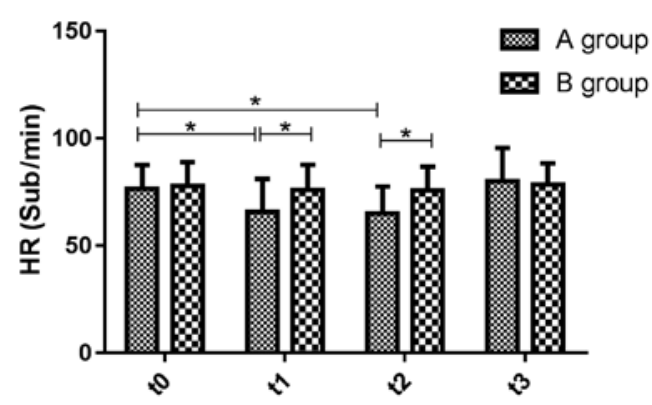

Figure 2. Comparison of HR between two groups of patients. Value of HR at $\mathrm{t} 1$ and $\mathrm{t} 2$ was lower than that at $\mathrm{t} 0$, and the difference between at $\mathrm{t} 3$ and at t0 has no statistical significance in group $\mathrm{A}(\mathrm{P}>0.05)$; the value of $\mathrm{HR}$ at $\mathrm{t} 1$, $\mathrm{t} 2$ and $\mathrm{t} 3$ was not different from that at $\mathrm{t} 0$ in group $\mathrm{B}(\mathrm{P}>0.05)$. The value of $\mathrm{HR}$ at $\mathrm{t} 1$ and $\mathrm{t} 2$ in group $\mathrm{B}$ was higher than that in group $\mathrm{A}(\mathrm{P}<0.05)$, and the difference of the value of $\mathrm{HR}$ at $\mathrm{t} 3$ between two groups has no statistical significance $(\mathrm{P}>0.05) .{ }^{*} \mathrm{P}<0.05$. The time of entering the operating room (t0), the beginning of the operation (t1), $10 \mathrm{~min}$ after the beginning of the operation (t2) and 10 min after operation (t3).

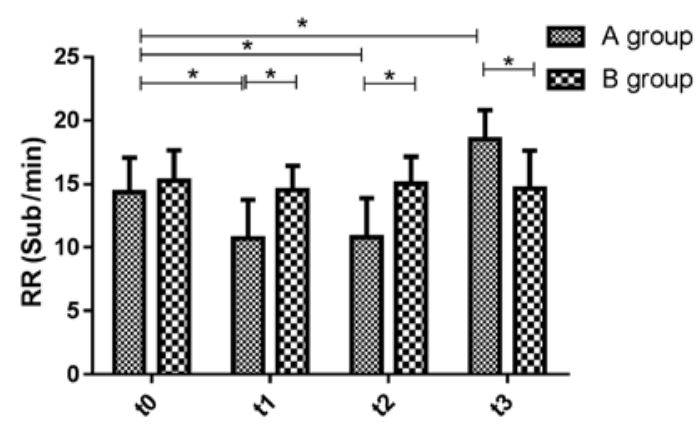

Figure 3. Comparison of RR between two groups of patients. Value of RR at $\mathrm{t} 1$ and $\mathrm{t} 2$ was lower than that at $\mathrm{t} 0$ and the value of $\mathrm{RR}$ at $\mathrm{t} 3$ was higher than that at $\mathrm{t} 0$ in group $\mathrm{A}(\mathrm{P}<0.05)$; the value of $\mathrm{RR}$ at $\mathrm{t} 1, \mathrm{t} 2$ and $\mathrm{t} 3$ was not different from that at t0 in group $B(P>0.05)$. The value of $R R$ at $t 1$ and $t 2$ in group $B$ was higher than that in group $A(P<0.05)$, and the value of $R R$ at $\mathrm{t} 3$ was lower than that in group $\mathrm{A}(\mathrm{P}<0.05)$. ${ }^{*} \mathrm{P}<0.05$. The time of entering the operating room $(\mathrm{t} 0)$, the beginning of the operation $(\mathrm{t} 1), 10 \mathrm{~min}$ after the beginning of the operation (t2) and 10 min after operation (t3).

Occurrence of adverse reactions within $2 \mathrm{~h}$ after operation. There were $32(15.76 \%)$ cases of dizziness, $6(2.96 \%)$ cases of nausea and $56(27.59 \%)$ cases of pain after operation in group A; In group B, 40 (12.78\%) cases of dizziness, 9 (2.90\%) cases of nausea and $30(9.58 \%)$ cases of pain. The difference has statistical significance between the two groups in the occurrence of pain $(\mathrm{P}<0.001)$, but it was not statistically significant in the occurrence of dizziness and nausea ( $P>0.05)$ (Table IV). 
Table III. Comparison of sedation score, amnesia and satisfaction of anesthesia after operation between the two groups.

\begin{tabular}{lcccc}
\hline Variables195/203 & Group A $(\mathrm{n}=203)$ & Group B $(\mathrm{n}=313)$ & $\mathrm{t} / \mathrm{Z}$ value & P-value \\
\hline Sedation score (point) & $4.12 \pm 0.11$ & $4.95 \pm 0.09$ & 8.651 & $<0.001$ \\
Amnesia [n (\%)] & & & -1.456 & 0.145 \\
Complete amnesia & $195(96.06)$ & $291(92.98)$ & & \\
Incomplete amnesia & $4(1.97)$ & $12(3.83)$ & & $<0.001$ \\
No amnesia & $4(1.97)$ & $10(3.19)$ & -5.076 & \\
Satisfaction of anesthesia & & & & \\
Very satisfied & $142(69.95)$ & $275(87.86)$ & 33 & \\
Satisfied & 50 & 5 & & \\
Neutral & 11 & & & \\
\hline
\end{tabular}

Table IV. Comparison of the occurrence of adverse reactions within $2 \mathrm{~h}$ after operation in two groups of patients [n (\%)].

\begin{tabular}{lccc}
\hline Groups & Dizziness & Nausea & Pain \\
\hline $\mathrm{A}, \mathrm{n}=203$ & $32(15.76)$ & $6(2.96)$ & $56(27.59)$ \\
$\mathrm{B}, \mathrm{n}=313$ & $40(12.78)$ & $9(2.90)$ & $30(9.58)$ \\
$\mathrm{t} / \chi^{2}$ value & 0.913 & 0.003 & 28.73 \\
P-value & 0.339 & 0.958 & $<0.001$ \\
\hline
\end{tabular}

\section{Discussion}

It has been pointed out by the World Health Organization (WHO) that the global gastric cancer cases are increasing year by year, by $\sim 14$ million new cases each year, and the number of gastric cancer in China ranks first in the world $(17,18)$. Therefore, gastric cancer, which poses a serious threat to human health and social and economic development, is the major public health problem in China and the world $(19,20)$. Because multiple tissues and organs are involved in radical gastrectomy, severe stress response will occur to cancer patients during operation, bringing some difficulties to anesthesia and postoperative management (21). At present, propofol combined with opiates or propofol combined with inhaled anesthetics are commonly used in patients undergoing radical gastrectomy. Propofol anesthesia has a rapid effect but no analgesic effect, so it needs to be used in combination with other analgesic drugs $(5,22)$. Remifentanil is a short-acting opioid analgesic with rapid onset of anesthesia, good analgesic effect but short duration of action (13). Sevoflurane is a new type of inhaled anesthetic with the advantages of less stimulation, stable hemodynamics during operation and easy control of anesthetic depth (12). A study has shown that patients with propofol combined with opiates have less postoperative complications and faster spontaneous respiratory recovery (23).

In this study, a retrospective cohort study was performed to observe the anesthetic effect of propofol combined with remifentanil and propofol combined with sevoflurane in cancer patients. Scientific, standardized and strict internal quality control was carried out in the process of data processing and analysis, so the results have high accuracy and reliability. The results showed that the difference was smaller in the values of MAP, HR and RR at the four time points in group B; the values of MAP and HR decreased at $t 1$ and $t 2$, and the value of $\mathrm{RR}$ decreased at $\mathrm{t} 1$ and $\mathrm{t} 2$, but increased at $\mathrm{t} 3$ in group $\mathrm{A}$ when compared to t0; the values of MAP, HR and RR at $\mathrm{t} 1$ and $\mathrm{t} 2$ in group B were higher than those in group A, and the value of RR at $\mathrm{t} 3$ was lower than that in group A; it indicated that propofol combined with sevoflurane anesthesia had little effect on the respiration and circulation of patients. The mechanism of propofol and remifentanil was related to the stimulation of vagus nerve and the inhibition of sinus node function, so the monitoring of heart rate should be strengthened during anesthesia $(20,24)$. Sevoflurane could cause peripheral vasodilation and myocardial inhibition in patients and was suitable for general anesthesia, because the time of waking up after operation in patients was short and the respiratory tract secretion was not increased (25).

It was found that patients' sedation score in group A was lower than that in group $B$, and the incidence of pain in group $A$ was higher than that in group B, indicating that patients had a high acceptance of propofol combined with sevoflurane anesthesia and a low incidence of adverse reactions. Cancer patients were prone to restlessness and other adverse reactions in general anesthesia due to pain, so sedation and analgesia effect were the main indicators to evaluate the anesthetic effect $(21,26)$. In addition to produce general anesthesia, sevoflurane also had vasodilator and analgesic effects, so it is more suitable for elderly patients and patients with cardiovascular insufficiency (27).

In conclusion, a retrospective cohort study was performed to analyze patients undergoing radical gastrectomy who had been anesthetized by propofol combined with sevoflurane and propofol combined with remifentanil. The results showed that patients undergoing radical gastrectomy with the combination of sevoflurane and propofol had stable respiration and circulation during anesthesia, quick recovery of early consciousness and low incidence of adverse reactions, having good sedation effects. Therefore, the combination of sevoflurane and propofol could be promoted in the clinical anesthesia of cancer patients.

\section{Acknowledgements}

Not applicable. 


\section{Funding}

No funding was received.

\section{Availability of data and materials}

The datasets used and/or analyzed during the present study are available from the corresponding author on reasonable request.

\section{Authors' contributions}

YF wrote the manuscript. YF and JL drafted the manuscript and were mainly devoted to collecting and interpreting the general data. HW and ZD recorded and analyzed the observation indicators. All the authors read and approved the final manuscript.

\section{Ethics approval and consent to participate}

The study was approved by the Ethics Committee of the First Bethune Hospital of Jilin University (Changchun, China). Signed informed consents were obtained from the patients or the guardians.

\section{Patient consent for publication}

Not applicable.

\section{Competing interests}

The authors declare that they have no competing interests.

\section{References}

1. Lan L, Zhao F, Cai Y, Wu RX and Meng Q: Epidemiological analysis on mortality of cancer in China, 2015. Zhonghua Liu Xing Bing Xue Za Zhi 39: 32-34, 2018 (In Chinese).

2. He J: Strengthen the cancer surveillance to promote cancer prevention and control in China. Zhonghua Zhong Liu Za Zhi 40: 1-4, 2018 (In Chinese).

3. Hayashi K, Murata K, Naito A, Kagawa Y, Kawai K, Mori R, Nose Y, Akiyama Y, Sakamoto T, Murakami K, et al: A case of resection of obstructive colon cancer associated with aspiration pneumonia, under combined epidural-spinal anesthesia. Gan To Kagaku Ryoho 44: 1970-1972, 2017 (In Japanese).

4. Kim MH, Kim DW, Kim JH, Lee KY, Park S and Yoo YC: Does the type of anesthesia really affect the recurrence-free survival after breast cancer surgery? Oncotarget 8: 90477-90487, 2017.

5. Lee KH, Rim SK, Lee JY, Lee SY, Lee SN, Lee EJ and Lee JH: Effects of pretreatment with intravenous palonosetron for propofol-remifentanil-based anesthesia in breast and thyroid cancer surgery: A double-blind, randomized, controlled study. Korean J Anesthesiol 67: 13-19, 2014.

6. Hao Z, Yali H, Xiangjun L, Fusheng D and Ruihua L: Comparison between propofol and propofol-remifentanil sedation under target-controlled infusion for impacted supernumerary teeth extraction surgery for children. Hua Xi Kou Qiang Yi Xue Za Zhi 35: 408-412, 2017 (In Chinese).

7. Peng K, Liu HY, Wu SR, Liu H, Zhang ZC and Ji FH: Does propofol anesthesia lead to less postoperative pain compared with inhalational anesthesia?: A systematic review and meta-analysis. Anesth Analg 123: 846-858, 2016.

8. Liu S, Gu X, Zhu L, Wu G, Zhou H, Song Y and Wu C: Effects of propofol and sevoflurane on perioperative immune response in patients undergoing laparoscopic radical hysterectomy for cervical cancer. Medicine (Baltimore) 95: e5479, 2016.

9. Chen Y, Liang M, Zhu Y and Zhou D: The effect of propofol and sevoflurane on the perioperative immunity in patients under laparoscopic radical resection of colorectal cancer. Zhonghua Yi Xue Za Zhi 95: 3440-3444, 2015 (In Chinese).
10. Hassan WM, Nasir YM, Zaini RH and Shukeri WF: Target-controlled infusion propofol versus sevoflurane anaesthesia for emergency traumatic brain surgery: Comparison of the outcomes. Malays J Med Sci 24: 73-82, 2017.

11. Zhang GH and Wang W: Effects of sevoflurane and propofol on the development of pneumonia after esophagectomy: A retrospective cohort study. BMC Anesthesiol 17: 164, 2017.

12. Wang C, Ni C, Li G, Li Y, Tao L, Li N, Wang J and Guo X: Effects of sevoflurane versus propofol on cerebrovascular reactivity to carbon dioxide during laparoscopic surgery. Ther Clin Risk Manag 13: 1349-1355, 2017.

13. Kratzer S, Mattusch C, Garcia PS, Schmid S, Kochs E, Rammes G, Schneider G, Kreuzer M and Haseneder R: Propofol and sevoflurane differentially modulate cortical depolarization following electric stimulation of the ventrobasal thalamus. Front Comput Neurosci 11: 109, 2017.

14. Recart A, Gasanova I, White PF, Thomas T, Ogunnaike B, Hamza M and Wang A: The effect of cerebral monitoring on recovery after general anesthesia: A comparison of the auditory evoked potential and bispectral index devices with standard clinical practice. Anesth Analg 97: 1667-1674, 2003.

15. Kong J, Wu SD and Su Y: Translumenal single-incision laparoscopy radical gastrectomy with $\mathrm{D} 2$ lymph node dissection for early gastric cancer - primary experience with less invasive surgery in China. J Laparoendosc Adv Surg Tech A 23: 141-145, 2013.

16. Andra $\mathrm{E}$ and Julie K: Bispectral index monitoring during sedation with sevoflurane, mmifazolam, and propofol. Anesthesiology 95: $11,2006$.

17. Moradkhani MR and Karimi A: Role of drug anesthesia and cancer. Drug Res (Stuttg) 68: 125-131, 2018.

18. Cho JS, Lee MH, Kim SI, Park S, Park HS, Oh E, Lee JH and Koo BN: The effects of perioperative anesthesia and analgesia on immune function in patients undergoing breast cancer resection: A prospective randomized study. Int J Med Sci 14: 970-976, 2017.

19. Sekandarzad MW, van Zundert AA, Doornebal CW and Hollmann MW: Regional anesthesia and analgesia in cancer care: Is it time to break the bad news? Curr Opin Anaesthesiol 30: 606-612, 2017.

20. Barela CA: The effect of anesthesia on cancer metastasis. Gastroenterol Nurs 40: 75-76, 2017.

21. Han Y, Han L, Dong M, Sun Q, Ding K, Zhang Z, Cao J and Zhang Y: Comparison of a loading dose of dexmedetomidine combined with propofol or sevoflurane for hemodynamic changes during anesthesia maintenance: A prospective, randomized, double-blind, controlled clinical trial. BMC Anesthesiol 18: 12, 2018.

22. Zhang L, Chen C, Wang L, Cheng G, Wu WW and Li YH: Awakening from anesthesia using propofol or sevoflurane with epidural block in radical surgery for senile gastric cancer. Int $\mathbf{J}$ Clin Exp Med 8: 19412-19417, 2015.

23. Annigeri RV and Patil RS: A retrospective analysis on anesthetic management during rigid bronchoscopy in children with foreign body aspiration: Propofol and sevoflurane with controlled ventilation. Anesth Essays Res 11: 871-874, 2017.

24. Tian HT, Duan XH, Yang YF, Wang Y, Bai QL and Zhang X: Effects of propofol or sevoflurane anesthesia on the perioperative inflammatory response, pulmonary function and cognitive function in patients receiving lung cancer resection. Eur Rev Med Pharmacol Sci 21: 5515-5522, 2017.

25. De Oliveira GS Jr, Bialek J, Rodes ME, Kendall MC and McCarthy RJ: The effect of sevoflurane compared to propofol maintenance on post-surgical quality of recovery in patients undergoing an ambulatory gynecological surgery: A prospective, randomized, double-blinded, controlled, clinical trial. J Clin Anesth 43: 70-74, 2017.

26. Tang L, Liu H, Wu Y, Li M, Li W, Jiang M, Hou J, Jiang Y, Xia Z and Meng Q: Sevoflurane may be more beneficial than propofol in patients receiving endoscopic variceal ligation and endoscopic variceal sclerotherapy: A randomized, double-blind study. Exp Ther Med 14: 3145-3152, 2017.

27. Robba C, Qeva E, Borsellino B, Aloisio S, Tosti G and Bilotta F: Effects of propofol or sevoflurane anesthesia induction on hemodynamics in patients undergoing fiberoptic intubation for cervical spine surgery: A randomized, controlled, clinical trial. J Anaesthesiol Clin Pharmacol 33: 215-220, 2017.

This work is licensed under a Creative Commons Attribution-NonCommercial-NoDerivatives 4.0 International (CC BY-NC-ND 4.0) License. 